\title{
2015 Proceedings
}

\author{
This Old Thing \\ Lauren Ashley Brallier, Vince Quevedo \\ Kent State University, USA
}

Keywords: Design, sustainability, upcycling, tablecloth

One aspect of sustainable fashion that I find fascinating is the challenge of making recycled fabrics appear anything but. Aesthetically, one would never guess that this elegant gown was once a dingy tablecloth. Thus, the title is 'This Old Thing'. Because I acquired the fabric from an estate sale, very little was known about its age or the fiber content. However, I was able to discern that it was formerly a tablecloth based on its rectangular shape, linear seaming, and numerous stains. Whatever special occasion warranted these linens, I wanted to ensure that the garment was just as special by designing something completely opposite from its original purpose.

As a result, I chose to create an evening gown that would be reminiscent of a fancy party. The inspiration for my design stemmed from champagne. Apart from the obvious colors, the body contouring of the gown evokes the sensuality of a champagne glass, while the beaded appliques capture the movement of rising bubbles. These appliques, which were repurposed from a home decor trim, were included first and foremost to hide the unsightly stains, but to also better convey the concept of champagne. To balance the design, I incorporated a slit at the base of the skirt to expose the gathered tulle underneath. In addition to upcycling, this garment also features innovative pattern and dart manipulations. I was able to eliminate the waistlines, as well as join the front and back princess seams into a cohesive curve, which emphasizes each hip.

The transformation of an old tablecloth into this conceptual gown demonstrates how sustainability does not have to sacrifice aesthetics. This upcycled design successfully challenges the stigma that used fabrics can only look salvaged. It is significant because it proves that upcycling can exist in high fashion and it can be beautiful. 

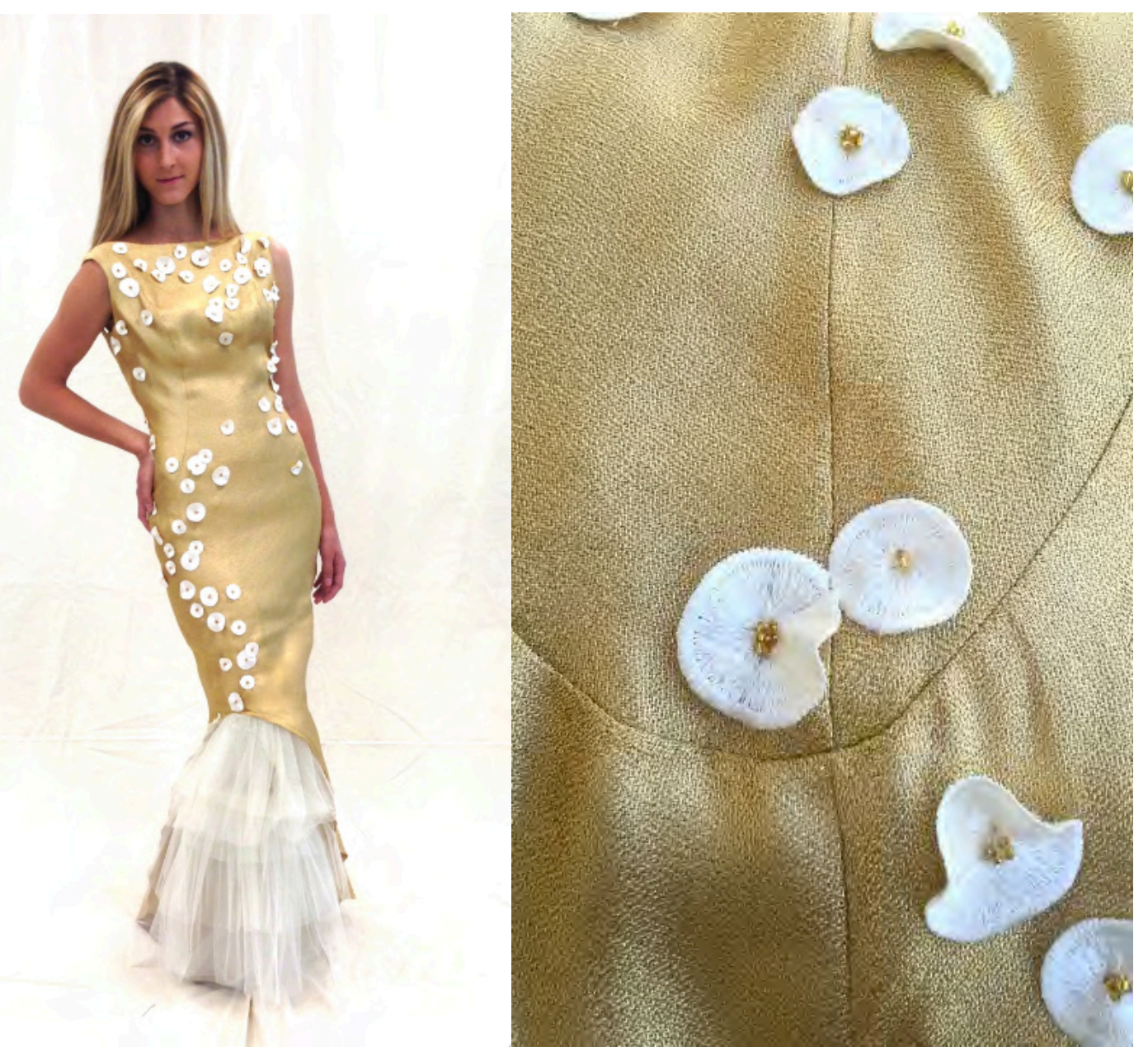

Page 2 of 2 